expedition this year to explore the mines further, and to work the ore which was left unextracted by the ancient miners.

\section{Atmospheric Pollution}

ThIRTY-EIGHT representatives of local authorities and other organizations co-operating with the Department of Scientific and Industrial Research met on May 31 at the offices of the Department in the usual half-yearly conference. Dr. G. M. B. Dobson, chairman of the Atmospheric Pollution Research Committee, presented, as usual, a report on the progress of the investigations carried out under the Committee. Systematic observations in connexion with the intensive survey of the pollution in and around the City of Leicester were begun on April 1. During the preceding four months, the survey staff were installing different standard measuring apparatus at twelve sites. The decision of the authorities at Leicester to equip and maintain a station for regular meteorological observations was greatly welcomed. The Conference also recorded its appreciation of the valuable assistance given by the public analysts of Glasgow, Hull and Sheffield, in an investigation of the possibility of combining a dust filter with apparatus for the determination volumetrically of sulphur dioxide in the atmosphere. A report was submitted through the Medical Officer of Health for Leeds on the analysis of dust samples collected in Leeds, Halifax and Huddersfield. The Conference endorsed a proposal made by the Research Committee that a meeting should be convened of public analysts and others who are directly responsible for making observations on behalf of co-operating bodies, to discuss technical problems and to interchange ideas on the measure. ment of atmospheric pollution. Mr. Brownhill Smith retired from the chairmanship of the Conference, having served for the maximum period of three consecutive years. Alderman David Adams, a representative of Newcastle-upon-Tyne, was elected chairman for the ensuing year.

\section{Study of Bird-Migration}

The British Trust for Ornithology has accepted responsibility for the future conduct of the principal scheme in Great Britain for the study of migration and other aspects of bird-life by the ringing method. This scheme was instituted in 1909 by Mr. H. F. Witherby, editor of British Birds, and has been maintained with the co-operation of readers of that journal. More than half a million birds have been marked to date, and the recoveries of a proportion of these have already added greatly to knowledge of the subject.
Important facilities for the work have at the same time been granted by the Trustees of the British Museum (Natural History), who are providing accommodation for the headquarters of the scheme in the Bird Room at South Kensington and permitting the Museum's address to be used. Rings will in future be inscribed "British Museum Nat. Hist. London", instead of "Witherby High Holborn London", with an individual identification number in addition as before. The scheme will now be directed by a special Bird-Ringing Committee, constituted as follows : Dr. A. Landsborough Thomson (chairman); Mr. A. W. Boyd; Mr. A. B. Duncan; Mr. P. A. D. Hollom; the Earl of Ilchester ; the Earl of Mansfield; Mr. H. F. Witherby ; and Miss E. P. Leach (hon. secretary). The headquarters' work will be in the hands of Miss Leach, who has had much experience of it as Mr. Witherby's collaborator in recent years. British Birds will continue to be the medium for publishing results.

\section{Institution of Civil Engineers}

WHEN the foundation stone of the present building of the Institution of Civil Engineers was laid in 1910 by the late Sir James Charles Inglis, then president of the Institution, the north-west corner could not be completed owing to the existence of a lease covering offices flanking that corner of the site. The demolition of the offices was, for various reasons, deferred until 1936; but the corner, with the consequent internal modifications in the library and reading-room, is now practically completed (Fig. 1), and Princes Street, which is to be known as Rennie Street from July 1, 1937, has also been widened to

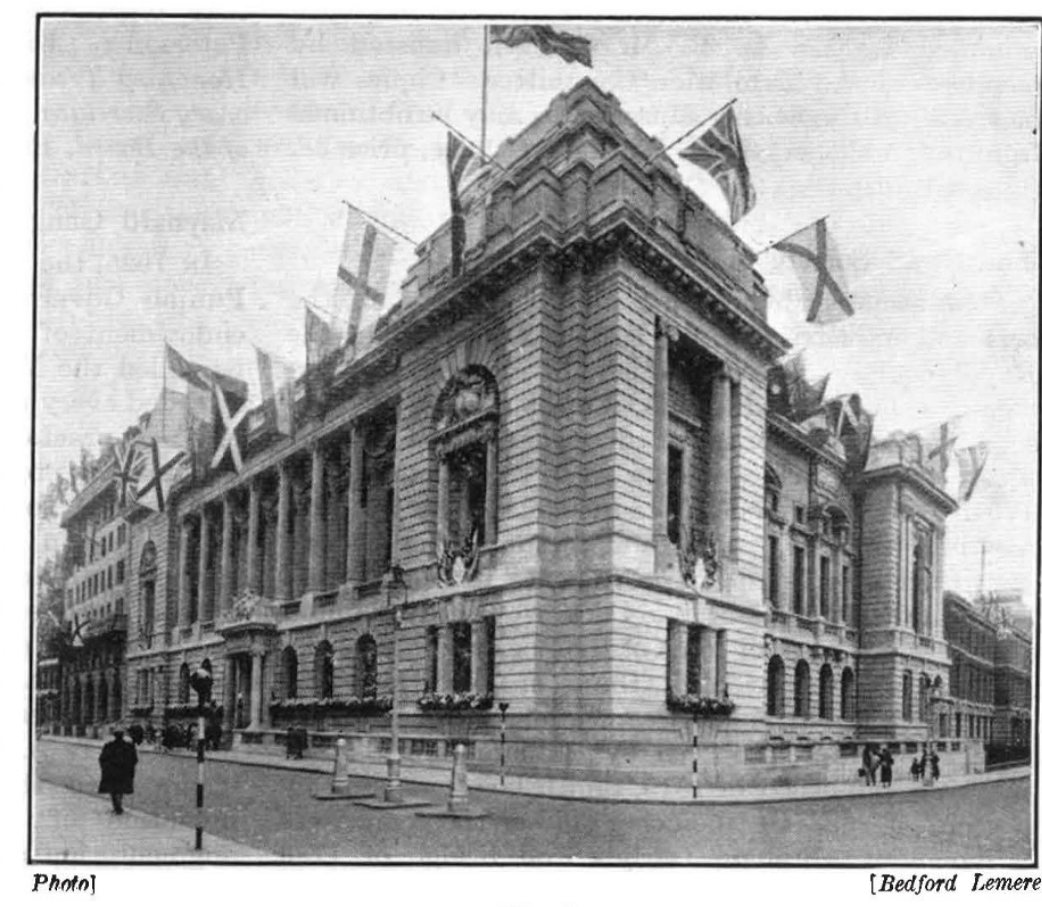

Fig. 1

Completed building of the Institution of Civil Enginears 